\title{
Prenatal glucocorticoid exposure programs adrenal PNMT expression and adult hypertension
}

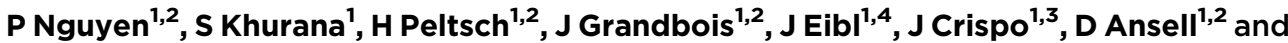 \\ T C Tai ${ }^{1,2,3,4}$
}

${ }^{1}$ Medical Sciences Division, Northern Ontario School of Medicine, Sudbury, Ontario, Canada Departments of ${ }^{2}$ Biology, ${ }^{3}$ Chemistry and Biochemistry and ${ }^{4}$ Biomolecular Sciences Program, Laurentian University, Sudbury, Ontario, Canada
Correspondence should be addressed to T C Tai

Email

tc.tai@nosm.ca

\begin{abstract}
Prenatal exposure to glucocorticoids (GCs) programs for hypertension later in life. The aim of the current study was to examine the impact of prenatal GC exposure on the postnatal regulation of the gene encoding for phenylethanolamine $N$-methyltransferase (PNMT), the enzyme involved in the biosynthesis of the catecholamine, epinephrine. PNMT has been linked to hypertension and is elevated in animal models of hypertension. Male offspring of Wistar-Kyoto dams treated with dexamethasone (DEX) developed elevated systolic, diastolic and mean arterial blood pressure compared to saline-treated controls. Plasma epinephrine levels were also elevated in adult rats exposed to DEX in utero. RT-PCR analysis revealed adrenal PNMT mRNA was higher in DEX exposed adult rats. This was associated with increased mRNA levels of transcriptional regulators of the PNMT gene: Egr-1, AP-2, and GR. Western blot analyses showed increased expression of PNMT protein, along with increased Egr-1 and GR in adult rats exposed to DEX in utero. Furthermore, gel mobility shift assays showed increased binding of Egr-1 and GR to DNA. These results suggest that increased PNMT gene expression via altered transcriptional activity is a possible mechanism by which prenatal exposure to elevated levels of GCs may program for hypertension later in life.
\end{abstract}
Key Words
- fetal programming
- hypertension
- adrenal
- phenylethanolamine $N$-methyltransferase
- Wistar-Kyoto rat
- glucocorticoids

Journal of Endocrinology (2015) 227, 117-127

\section{Introduction}

The hypothesis of the Fetal Origins of Adult Disease, proposed by Barker (Barker 1995, Barker et al. 2006) associates low birth weight with the onset of cardiovascular disease later in life, a phenomenon otherwise known as fetal programming. This is mediated in part by adaptation of the fetus to adverse conditions that are encountered during development in utero. Examples of such stressors include maternal nutrient restriction, hypoxia, physical trauma, as well as exposure to alcohol and nicotine. There is a large and growing body of evidence linking an adverse prenatal environment to the fetal programming of cardiovascular disease in adult life (Vehaskari \& Woods 2005, Cottrell \& Seckl 2009, Alexander et al. 2015). Low birth weight and developmental programming of hypertension has been correlated with impaired kidney development and dysregulated renin-angiotensinaldosterone system (Baum 2010, Goyal et al. 2010), impaired vascular structure and function (Pladys \& Sennlaub 2005, Ligi et al. 2010), as well as altered activity of the hypothalamic-pituitary-adrenal (HPA) (Bouret 2009, Boyne et al. 2009), and the sympatho-adrenal (SA) axes (Young 2002, Johansson et al. 2007). Further, studies

Published by Bioscientifica Ltd 
have observed that exposure to high doses of glucocorticoids (GCs) during fetal development, generated either as a consequence of maternal stressors or administered antenatally also reduces birth weight and leads to development of essential hypertension later in life (Edwards et al. 1993, Drake et al. 2007). The role of GCs in the fetal programming of hypertension has been investigated in sheep (Dodic et al. 2002), rats (Benediktsson et al. 1993, Levitt et al. 1996, Ortiz et al. 2002, O'Regan et al. 2008, Habib \& Gattineni 2011), as well as in humans (Karemaker et al. 2006). However, the exact mechanisms by which GC-mediated fetal programming of hypertension occurs requires further investigation.

GCs are hormones which play a major role in the development of various organ systems in utero (Drake et al. 2007). They are also an important component of the HPA axis as part of the body's response to stress, acting upon the adrenal medulla to regulate the biosynthesis and secretion of the catecholamine epinephrine, a neurotransmitter/neurohormone that is physiologically significant in the sympathetic control of blood pressure and cardiovascular activity (Borkowski \& Quinn 1984, Wong 2006). Its synthesis and release is regulated by the HPA and SA axes during the neuroendocrine response to stress (Axelrod 1976, Wong 2006). Elevated plasma levels of epinephrine are observed in humans with essential hypertension (Buühler 1982) as well as various animal models of hypertension, including the spontaneously hypertensive rat (SHR) (Jablonskis \& Howe 1994).

The biosynthesis of epinephrine is regulated by phenylethanolamine $\mathrm{N}$-methyltransferase (PNMT), the terminal enzyme in the catecholamine biosynthetic pathway. In hypertensive rats, adrenal PNMT mRNA, protein and enzyme activity are elevated compared to their non-hypertensive counterparts resulting in the increased adrenergic function associated with hypertension (Axelrod 1976, Reja et al. 2002). Numerous genetic linkage studies have investigated PNMT as a candidate gene for hypertension in rats and humans (Kaneda et al. 1988, Hoehe et al. 1992, Koike et al. 1995). The differences in PNMT expression in hypertension are not attributed to polymorphisms within the PNMT gene suggesting that altered regulation of the PNMT gene can account for changes in its expression (Nguyen et al. 2009, Khurana et al. 2015). Studies to date have identified key regulatory transcription factors involved in trans-activation of the PNMT promoter in adrenal chromaffin and PC12 cells, such as Egr-1, Sp1, AP-2, HIF-1 $\alpha$, MAZ and the glucocorticoid receptor (GR) (Ebert et al. 1994, Tai et al. 2002, 2009, 2010a, Her et al. 2003). GCs are key regulators of PNMT, and we have previously demonstrated that the induction of PNMT gene expression in vitro upon GC administration is mediated by GC response elements (GRE) within the PNMT promoter (Tai et al. 2002). Further, altered activity of the transcription factors regulate PNMT not only in vitro (Tai et al. 2002, 2010a), but also in immobilization stress (Tai et al. 2007, Wong et al. 2008) as well as in a genetic model of hypertension, the SHR (Nguyen et al. 2009).

The aim of this study was to investigate the effects of prenatal GC administration on the molecular mechanisms involved in the dysregulation of adrenal PNMT in a fetal programming model of hypertension, by examining expression of transcriptional regulators of the PNMT gene in male offspring of Wistar-Kyoto (WKY) dams injected with dexamethasone (DEX). Results from this study show changes in key transcription factors regulating PNMT expression in the adrenal glands of DEX-treated male WKY offspring, coincident with elevated adrenal PNMT expression. This suggests that altered regulation of adrenal PNMT expression, along with coincident elevated epinephrine biosynthesis, is an important component of GC-induced fetal programming of adult hypertension.

\section{Materials and methods}

\section{Animals}

Male $(n=3)$ and female $(n=12)$ WKY rats were obtained from Charles River Laboratories (Montreal, QC, Canada) at 10 weeks of age. All animals were supplied with food (Harlan Teklad standard rat chow; Indianapolis, IN, USA) and water ad libitum. All animal procedures were approved by the Laurentian University Animal Care Committee, in accordance with guidelines from the Canadian Council on Animal Care.

\section{Breeding and dosing regimen}

After acclimating to housing conditions for 2 weeks, males were introduced to virgin females overnight during estrous cycles until vaginal plugs were observed (denoted day 1 of pregnancy). Pregnant females were caged individually for the remainder of pregnancy. Upon entering the third trimester (gestational days 15-21), pregnant female WKY rats were administered daily s.c. injections of DEX $(0.1 \mathrm{mg} / \mathrm{kg}$ per day), or saline vehicle (control group; 4\% ethanol/0.9\% saline solution) (Levitt et al. 1996, Oliveira et al. 2006).

Published by Bioscientifica Ltd 


\section{Physiological measurements}

Male offspring of WKY dams were weaned at 3 weeks of age, and consequently subject to weekly blood pressure measurements via a non-invasive tail-cuff plethysmography method (CODA 6; Kent Scientific, Torrington, CT, USA) as previously described (Feng et al. 2008, Nguyen et al. 2009). Animals were adapted to the measurement process during the first week of measurement. For a given session, animals were introduced into plexiglass holders kept on thermal heating pads set to $30^{\circ} \mathrm{C}$ with blood pressure measurement cuffs placed on the base of the tail. Animals were acclimated to measurement conditions for $10 \mathrm{~min}$ prior to 30 consecutive blood pressure measurements over $30 \mathrm{~min}$. Body weights were also monitored during the measurement period. All measurements were conducted during the light cycle, between $0800 \mathrm{~h}$ and $1700 \mathrm{~h}$.

\section{Tissue collection}

Following blood pressure measurements at 17 weeks of age, animals were anesthetized with i.p. administration of ketamine (Ketalean; Bimeda, Cambridge, ON, USA) and xylazine (Rompun; Bayer, Etobicoke, ON) (75 mg ketamine, $5 \mathrm{mg}$ xylazine per $\mathrm{kg}$ body weight), then sacrificed by immediate decapitation, as described previously (Nguyen et al. 2009). Adrenal glands were frozen on dry ice, and subsequently stored at $-80^{\circ} \mathrm{C}$ until use.

\section{RNA extraction}

Total RNA was extracted from left adrenal glands of WKY rats via mechanical disruption of tissue (TissueLyser; Qiagen) in Trizol Reagent (Sigma-Aldrich) as described previously (Nguyen et al. 2009). Isolated total RNA pellets were resuspended in diethylpyrocarbonate (DEPC)-treated nuclease-free water and concentrations determined using spectrophotometric measurement of absorbance at $260 \mathrm{~nm}$ (NanoDrop; Nanodrop Technologies, Wilmington, DE, USA).

\section{Semi-quantitative RT-PCR}

Two micrograms of total RNA was treated with DNAse I (Sigma-Aldrich), and cDNA subsequently synthesized using Moloney Murine Leukemia Virus Reverse Transcriptase enzyme (Promega) as previously described (Nguyen et al. 2009). PCR was performed in $25 \mu \mathrm{l}$ reaction volumes containing $125 \mathrm{ng}$ of cDNA, using GoTaq Flexi DNA polymerase (Promega) along with $200 \mu \mathrm{M}$ of dNTPs, and $25 \mathrm{ng}$ of forward and reverse primer sequences specific for
PNMT, tyrosine hydroxylase (TH), dopamine $\beta$-hydroxylase (DBH), chromogranin A, Egr-1, Sp1, GR, AP-2 and cyclophilin (housekeeping control) (Sigma Genosys, Oakville, ON, USA). The primer sequences used for the amplification were the same as previously described (Nguyen et al. 2009). PCR products were resolved on $1.5 \%$ agarose gels and stained with ethidium bromide.

\section{Protein extraction}

Protein was extracted from right adrenal glands of WKY rats through mechanical disruption of tissue (TissueLyser; Qiagen) in RIPA lysis buffer solution (25 mM Tris- $\mathrm{HCl}$, $150 \mathrm{mM} \mathrm{NaCl}, 0.1 \%$ SDS, $2 \mathrm{mM}$ EDTA, 1\% sodium deoxycholate, 1\% NP-40, $0.5 \mathrm{mM}$ phenylmethylsulfonyl fluoride (PMSF; Sigma-Aldrich) and protease inhibitors (Complete mini-EDTA free protease inhibitor cocktail tablet; Roche Diagnostics), as previously described (Nguyen et al. 2009). Lysates were incubated on ice for $10 \mathrm{~min}$ prior to centrifugation $\left(12000 \mathrm{~g}\right.$ for $20 \mathrm{~min}$ at $4{ }^{\circ} \mathrm{C}$ ) to pellet cell debris, after which supernatant was collected and stored at $-80^{\circ} \mathrm{C}$. Protein concentrations were determined by the Bradford method (BioRad).

\section{Western immunoblotting}

Western blot analysis of protein targets was performed as previously described (Tai et al. 2002, 2007, 2009). Briefly, $50 \mu \mathrm{g}$ of total protein per sample was resolved on $12 \%$ SDSpolyacrylamide gels and subsequently transferred to PVDF membranes (BioRad) in transfer buffer $(48 \mathrm{mM}$ Tris, $39 \mathrm{mM}$ glycine, $0.037 \%$ SDS, $20 \%$ methanol) at $100 \mathrm{~V}$ for $1 \mathrm{~h}$. Transfer and equal loading of protein were verified by Ponceau S stain (Sigma). Membranes were incubated for $1 \mathrm{~h}$ at $4^{\circ} \mathrm{C}$ in blocking solution containing 5\% skim milk in Tris-buffered saline with Tween-20 (TBST; $10 \mathrm{mM}$ Tris$\mathrm{HCl}, 150 \mathrm{mM} \mathrm{NaCl}, 0.05 \%$ Tween-20), then rinsed in TBST $(3 \times 10 \mathrm{~min})$ before overnight incubation with primary antibodies specific for rat PNMT (Immunostar, Hudson, WI, USA; 1:3000 dilution), Egr-1 (C-19, Santa Cruz Biotechnologies; 1:1000), Sp1 (PEP-2, Santa Cruz; 1:2500), GR (M-20, Santa Cruz; 1:2000), AP-2 (Millipore, Billerica, MA, USA, 1:2000) in 5\% skim milk-TBST. Membranes were then rinsed in TBST $(3 \times 10 \mathrm{~min})$ and incubated with HRP-conjugated secondary IgG (Sigma; 1:5000) in 5\% skim milk-TBST for $1 \mathrm{~h}$, followed by a final series of rinses in TBST $(3 \times 10 \mathrm{~min})$. Proteins were then detected by enhanced chemiluminescence (Haan \& Behrmann 2007) and subsequent exposure to film (Pierce, Rockford, IL, USA).

Published by Bioscientifica Ltd 


\section{Gel shift mobility assay}

GMSAs were performed using $20 \mu \mathrm{g}$ of total protein, combined with double-stranded oligonucleotides for Egr-1, Sp1, GR and AP-2 which were 5' end-labeled with $\left[\gamma_{-}{ }^{32} \mathrm{P}\right]$ ATP using T4 polynucleotide kinase (Promega) as described previously (Tai et al. 2002, Nguyen et al. 2009). Proteins and probes were incubated in binding buffer (20 mM Tris- $\mathrm{HCl}$ (pH 7.5), $40 \mathrm{mM} \mathrm{KCl,} \mathrm{12 \%} \mathrm{glycerol,}$ $0.5 \mathrm{mg} / \mathrm{ml}$ bovine serum albumin, $5 \mathrm{mM} \mathrm{MgCl}_{2}, 1 \mathrm{mM}$ DTT and $4 \mu \mathrm{g}$ poly (dA-dT) ) in $25 \mu$ reaction volumes. Supershift assays were conducted to confirm protein/DNA complexes, wherein antibodies specific for Egr-1, Sp1, GR and AP-2 were added to binding reactions. After incubation on ice for $1 \mathrm{~h}$, protein/DNA binding complexes were resolved on $7 \%$ polyacrylamide gels with subsequent exposure to film (Pierce).

\section{Plasma corticosterone levels}

Trunk blood was collected in EDTA-coated blood collection vials (Becton Dickinson, Mississauga, CA, USA) and centrifuged at $1500 \boldsymbol{g}$ for $20 \mathrm{~min}$. Plasma was subsequently collected and stored at $-80{ }^{\circ} \mathrm{C}$ until use. Corticosterone levels were determined in duplicate for each sample $(n=4$ per group) using Milliplex immunodetection assays according to the manufacturer's protocol (Millipore).

\section{Plasma epinephrine levels}

Catecholamine levels were quantified using a CAT ELISA kit as per manufacturer's protocol (Immunobiological Laboratories International, Toronto, CA, USA). Plasma samples ( $n=4$ per group) were first extracted on extraction plates coated with boronate affinity gel, with subsequent acylation and release. Plasma samples, along with catechol-O-methyltransferase (COMT), and standards for epinephrine were added to 96-well microtiter plates coated with anti-rabbit IgG. COMT metabolizes epinephrine into metanephrine. Following metabolism, anti-serum for epinephrine was added to the plate, which was allowed to incubate for $2 \mathrm{~h}$ at room temperature. Plates were washed six times using a $1 \mathrm{X}$ wash buffer containing TBS-T. Enzyme conjugate was then added for a $1 \mathrm{~h}$ incubation period at room temperature, followed by another series of washes prior to the addition of the substrate solution, which was allowed to incubate for $40 \mathrm{~min}$ at room temperature. A stop solution (1M $\mathrm{NaOH}, 0.25 \mathrm{M}$ EDTA) was added to stop the substrate reaction before measuring optical density using a spectrophotometer at $405 \mathrm{~nm}$. Sample concentrations were determined from standard curves.

\section{Quantitation and statistical analysis}

Images of resolved PCR gels and autoradiographs were documented using Chemidoc XRS imaging system (BioRad), with subsequent densitometric analysis performed with QuantityOne software (BioRad). All data is represented as mean \pm s.E.M. For the blood pressure measurements, the data set was analyzed by fitting each data set to a second order polynomial equation (Least Squares method for fitting), followed by Extra Sum-ofSquares $F$ Test to compare the parameters of each equation to determine if the curves were significantly different or if one curve would adequately fit both data sets. For all the other experimental measurements, a $t$-test was performed between the saline and DEX groups. All analyses were done using GraphPad Prism software (GraphPad, La Jolla, CA, USA). Values of $P \leq 0.05$ were considered statistically significant.

\section{Results}

\section{Physiological measurements}

Blood pressure was measured in male offspring from 4 to 17 weeks of age (Fig. 1A, B and C). Average systolic blood pressure was higher in the DEX offspring as early as 4 weeks of age, and this persisted throughout the remainder of the measurement period, up to 17 weeks of age. Elevations of similar magnitude were also observed in the DEX-treated offspring with respect to diastolic blood pressure, and mean arterial blood pressure over the same time period. Body weight was also monitored during the measurement period (Fig. 1D). DEX-treated male offspring had lower average body weight than their saline counterparts from 7 weeks of age up to 17 weeks of age.

\section{PNMT expression and plasma epinephrine concentration}

Semi-quantitative RT-PCR was performed to compare levels of PNMT gene expression. At 17 weeks of age, adrenal PNMT mRNA levels were significantly higher within DEX-treated offspring compared to that of their saline-treated counterparts (Fig. 2A; 1.5-fold). The transcripts of $\mathrm{TH}$ and $\mathrm{DBH}$ from the catecholamine biosynthetic pathway were also elevated in the adrenals of prenatally DEX-exposed animals (data not shown).

Published by Bioscientifica Ltd 

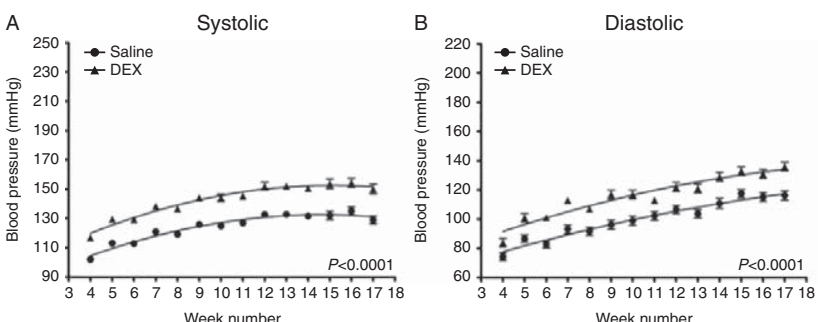

Figure 1

Blood pressure and body weight of male offspring born to saline or DEXtreated Wistar-Kyoto dams. The systolic (A), diastolic (B) and mean arterial blood pressure (C) were elevated, while body weight was lower (D) in prenatally DEX-exposed offspring. The data set was analyzed by fitting each data set to a second order polynomial equation (Least Squares method for fitting), followed by Extra Sum-of-Squares $F$ Test to compare

Western Blot analysis showed increased levels of PNMT protein present in DEX-treated offspring (Fig. 2B 1.44-fold). Plasma corticosterone and epinephrine levels were also assessed; there were no significant changes in plasma corticosterone levels in DEX-treated offspring compared to saline controls (Fig. 2C), while plasma epinephrine levels were increased in DEX-treated rats (Fig. 2D; twofold).

A
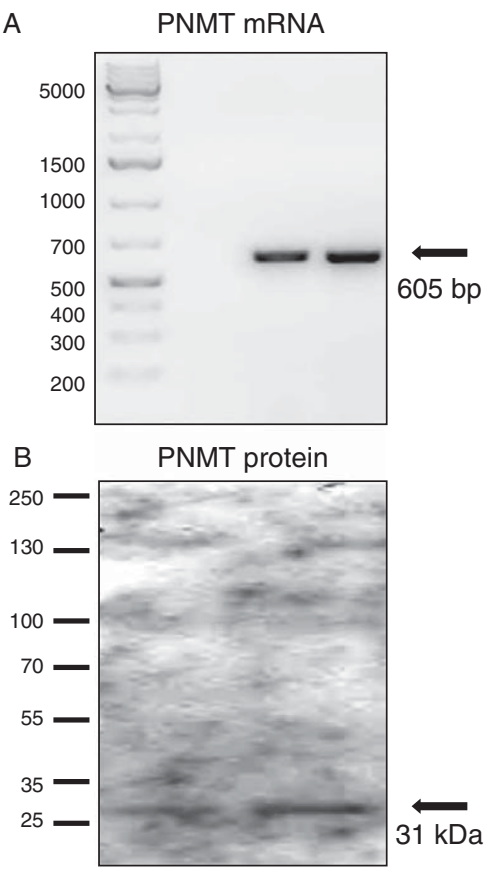
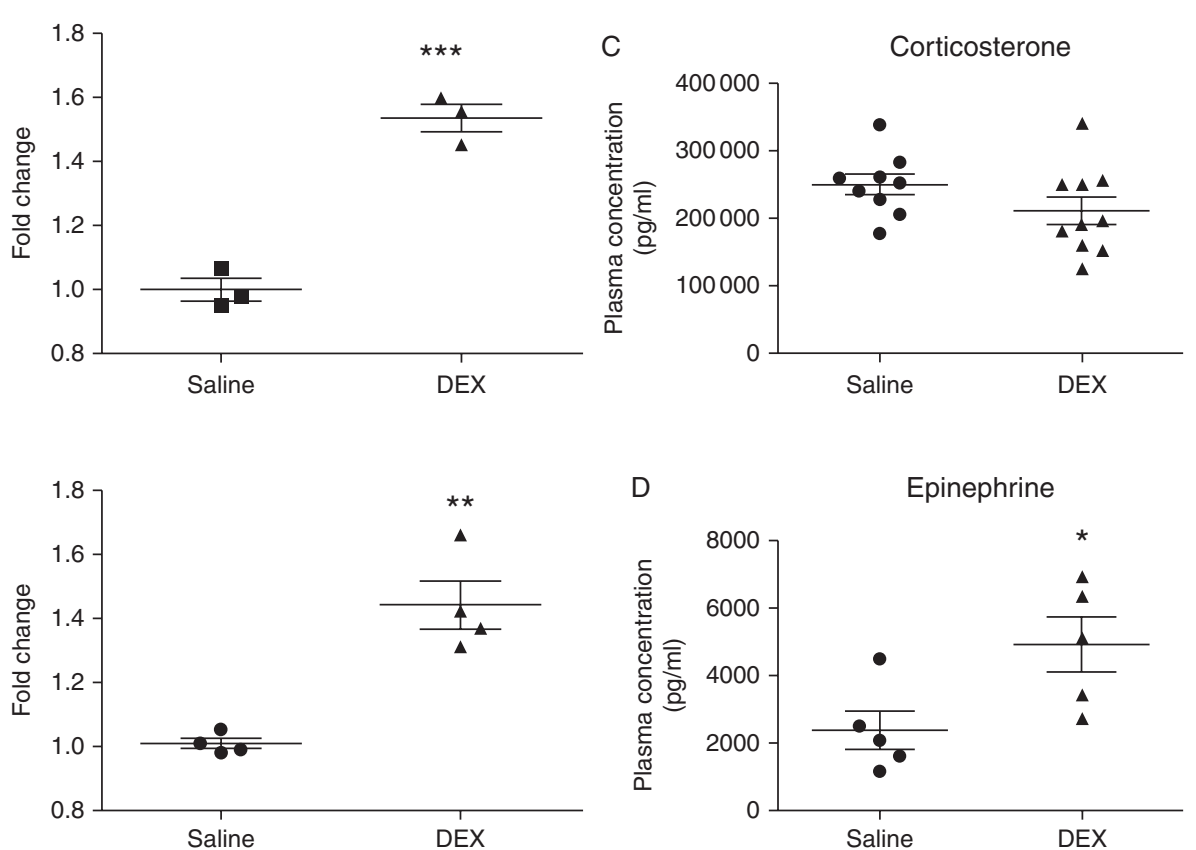
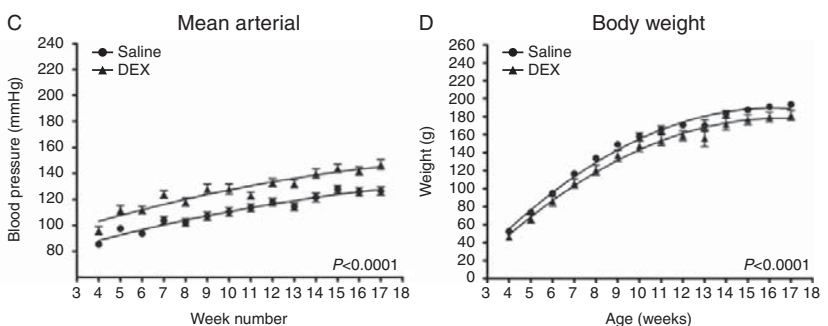

the parameters of each equation to determine if the curves were significantly different or if one curve would adequately fit both data sets. We found significant differences between the curves (saline vs DEX, $P<0.0001$ ). Please note that the $Y$-axes do not begin at 0 for Fig. $1 \mathrm{~A}, \mathrm{~B}$ and $\mathrm{C}$.

\section{Alteration of transcriptional regulators of PNMT}

To determine if altered PNMT expression in the DEXtreated offspring could be due to elevated transcriptional activity of PNMT, semi-quantitative RT-PCR was performed to examine expression of transcription factors Egr-1, Sp1, GR and AP-2 (Fig. 3). Egr-1 mRNA levels were highly elevated in DEX-treated offspring compared
Figure 2

Effects of prenatal DEX exposure on PNMT expression and plasma corticosterone and epinephrine levels. Representative images of (A) semi-quantitative RT-PCR performed on rat adrenal mRNA, (B) Western immunoblotting performed on rat adrenal whole-cell lysate for PNMT, as well as plasma corticosterone (C) and (D) epinephrine levels determined by Printed in Great Britain immunoassay. Fold changes between saline controls vs DEX-treated males are presented as mean \pm S.E.M. (normalized to cyclophilin A control in PCR, and Ponceau $S$ for the Western blot). Significant difference between groups designated as $* P \leq 0.05, * * P \leq 0.005, * * * P \leq 0.0001$. Please note that the $Y$-axes do not begin at 0 for the graphical representation in Fig. $2 A$ and $B$. 
to saline-treated controls ( 2.5 fold). Similar increases were found with respect to AP-2 (1.9-fold), and GR mRNA in DEX-treated offspring (1.9-fold). Analysis of Sp1 mRNA showed not as much of an increase, but was still significant (1.18-fold). In addition, Western Blot analysis showed increased levels of Egr-1 (1.5-fold) and GR (1.7-fold) compared to SAL males (Fig. 4). No differences in Sp1 or AP-2 protein were observed between groups. The differences in expression of Egr-1 and GR protein are comparable to the changes in their respective mRNA levels. The ability of these proteins to bind and activate the PNMT promoter was also assessed using gel shift mobility assays (Fig. 5). In DEX-treated male offspring, there was increased binding of Egr-1 (1.7-fold) as well as GR to DNA (2.0-fold) compared to saline-treated rats. This is reflective of the increased levels of Egr-1 and GR mRNA and protein present in DEX treated males. No significant changes in binding were observed with AP-2, and only a slight increase with Sp1. DNA-protein complexes were confirmed by antibody supershift (data not shown).

\section{Discussion}

Antenatal GC administration has previously been used experimentally to program offspring for adult hypertension (Benediktsson et al. 1993, Levitt et al. 1996, Ortiz et al.
2002, O'Regan et al. 2008, Habib \& Gattineni 2011). In this study, we demonstrate that administration of the synthetic GC, DEX during the third trimester of gestation results in elevated systolic, diastolic, and mean arterial blood pressure in WKY male rats. These changes are observed as early as 4 weeks of age, and are maintained up to 17 weeks of age. The administration of DEX has been well-established as a paradigm for programming of hypertension in rat offspring (Khurana et al. 2015). Our results are in agreement with previous studies that have shown programming of hypertension in offspring upon prenatal administration of DEX (Levitt et al. 1996, O'Regan \& Kenyon 2004, Woods \& Weeks 2005, Wyrwoll et al. 2007), corticosterone (Dodic et al. 2002, Singh et al. 2007) or betamethasone (Shaltout et al. 2009), during the third trimester of gestation.

Further, our study shows that DEX-treated offspring had a reduced level of growth compared to their saline-treated counterparts throughout the study period. Typically, DEX administration leads to offspring with reduced birth weight (Levitt et al. 1996), with accelerated postnatal growth (O'Regan \& Kenyon 2004), resulting in hypertension and obesity associated with metabolic syndrome. However, it has also been shown that offspring born with low birth weight can also experience slowed or stunted growth, with persistently reduced body weight throughout childhood without influence from
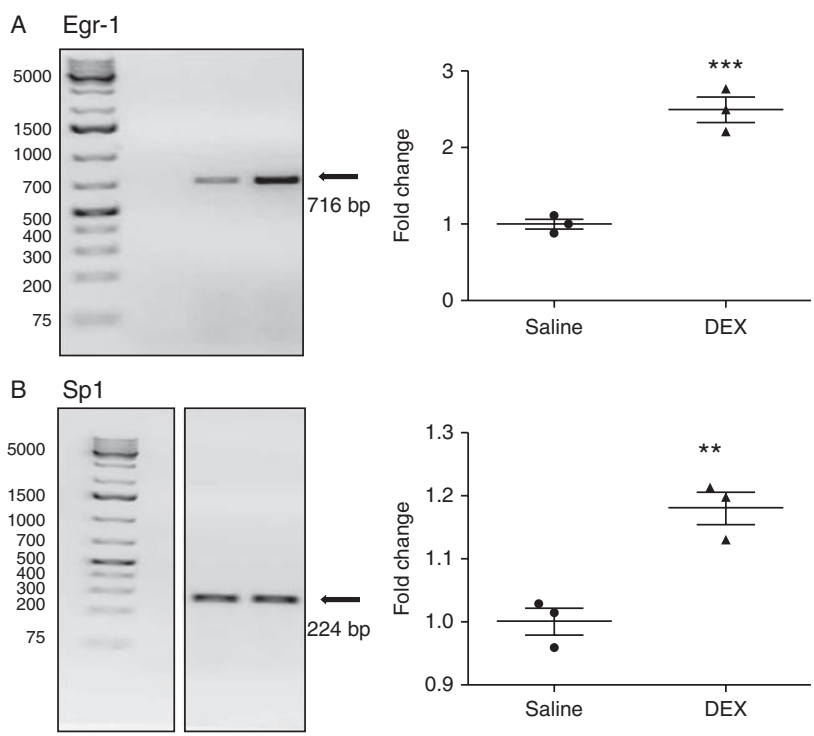

C
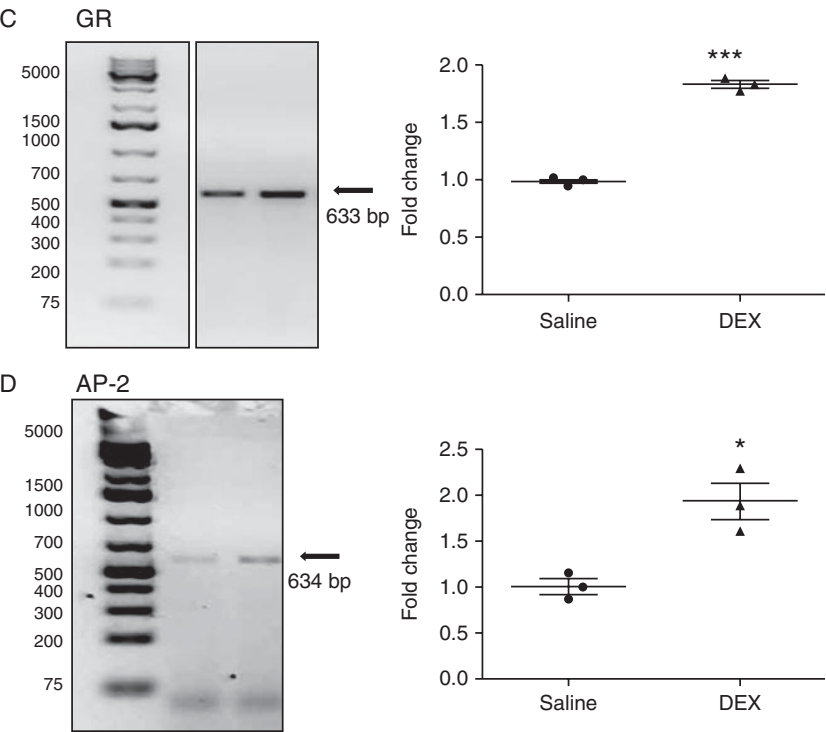

Figure 3

Effects of prenatal DEX exposure on transcriptional regulators by RT-PCR. Representative images of semi-quantitative RT-PCR performed on rat adrenal mRNA for Egr1 (A), Sp1 (B), GR (C) and AP-2 (D). Fold changes in expression levels between saline controls vs DEX-treated males are

presented as mean \pm S.E.M. (normalized to cyclophilin A). Significant difference between groups designated as $* P \leq 0.05, * * P \leq 0.005$, $* * * P \leq 0.0001$. Please note that the $Y$-axis does not begin at 0 for the graphical representation in Fig. 3B.

Published by Bioscientifica Ltd. 

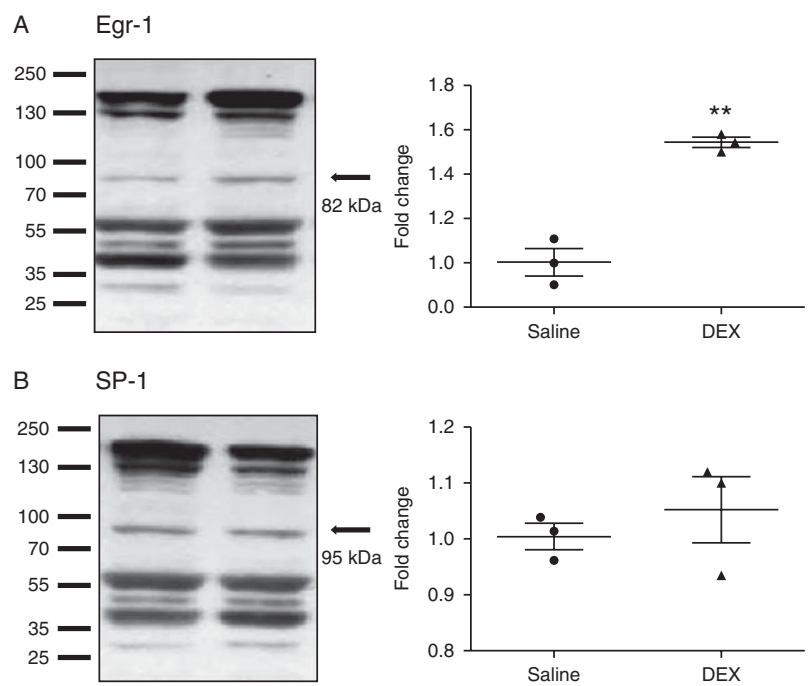

Figure 4

Analysis of the transcriptional regulators of PNMT by Western immunoblot. Representative images of semi-quantitative western blots performed on rat adrenal mRNA for Egr1 (A), Sp1 (B), GR (C) and AP-2 (D). Fold changes in expression levels between saline controls vs DEX-treated males are

environmental insults such as poor living conditions, and still develop adult hypertension (Barker et al. 2006). It is likely that the population of offspring in this study had developed hypertension according to this paradigm. Therefore, prenatal stresses on the offspring indeed program for hypertension later in life. However, the
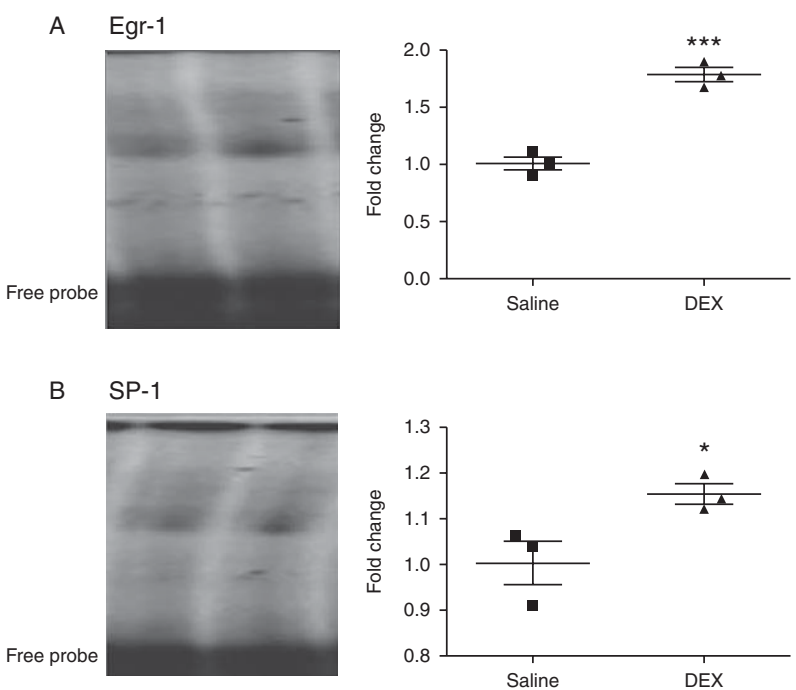

\section{Figure 5}

Comparison of affinity for binding the PNMT promoter sequence of adrenal gland protein. Representative panel of Gel Mobility Shift Assays (GMSA) performed on rat adrenal whole-cell lysates with radiolabeled oligonucleotides specific for Egr1 (A), Sp1 (B), GR (C) and AP-2 (D).
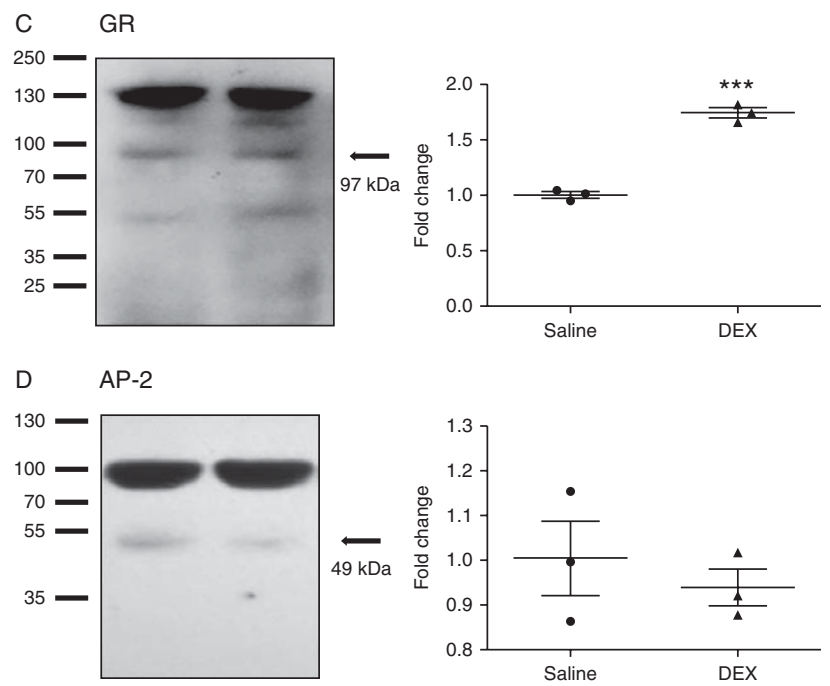

presented as mean \pm S.E.M. (equal loading confirmed by Ponceau S staining) Significant difference between groups designated as $* * P \leq 0.005$, $* * * P \leq 0.0001$. Please note that the $Y$-axes do not begin at 0 for the graphical representation in Fig. 4A, B and D.

severity of hypertension and other associated risk factors for cardiovascular disease can be influenced greatly by environmental factors (Alexander 2007).

This study provides the first evidence that prenatal GC administration leads to increased PNMT gene expression in adult adrenal glands via altered transcriptional activity,

C GR
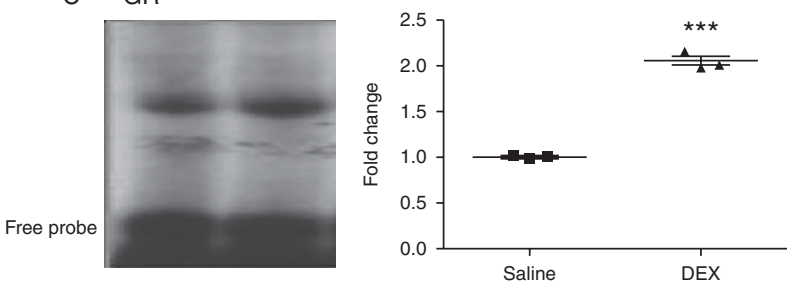

D $\quad$ AP-2

Free probe

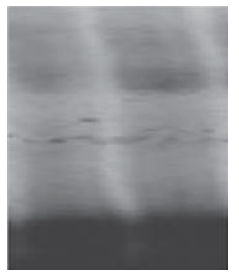

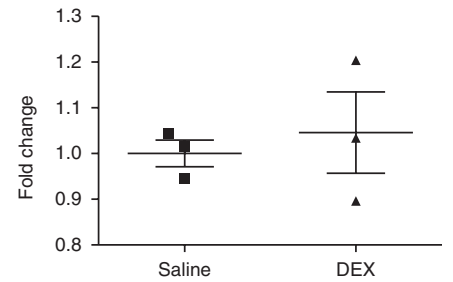

Fold changes in binding levels between saline control vs DEX-treated males are presented as mean \pm S.E.M. Significant difference between groups is designated by $* P \leq 0.05, * * * P \leq 0.0001$. Please note that the $Y$-axes do not begin at 0 for the graphical representation in Fig. $5 B$ and $D$. 
resulting in elevated levels of circulating epinephrine. In particular, the observed elevation in PNMT expression in DEX-treated WKY offspring is associated with increased expression and activity of transcriptional regulators Egr-1 and GR. This is reflected for the most part in associated protein levels, similar to previous observations made in other animal models of hypertension such as the SHR (Reja et al. 2002, Nguyen et al. 2009), and experimental stress-induced models (Tai et al. 2007, Wong et al. 2008). In addition, Egr-1 and GR bind with greater affinity to DNA in the DEX-treated WKY offspring, suggesting these transcription factors are prominent in the dysregulation of PNMT in this model of hypertension. This finding suggests that prenatal GCs can alter expression of PNMT in adulthood. This has tremendous implications considering the role of epinephrine in blood pressure regulation and the link between PNMT and hypertension (Axelrod 1976, Hoehe et al. 1992, Koike et al. 1995, Wong 2006).

Plasma corticosterone levels were not significantly increased in the GC-programmed offspring compared to their saline-treated counterparts, an observation which contrasts some studies examining GC-induced hypertension (Levitt et al. 1996, Singh et al. 2007, O'Regan et al. 2008). Typically, such studies refer to the importance of the HPA and its potential as a programming target (Lesage et al. 2006). However, there are studies which have either found no changes, or even reduced plasma levels of corticosterone (Nyirenda et al. 2001, Lesage et al. 2004) in response to fetal programming by GC administration.

PNMT and epinephrine synthesis by adrenal chromaffin cells can be regulated by both the HPA and SA axis. In hormonal regulation of PNMT, chromaffin cells in the adrenal medulla are stimulated to produce epinephrine due to the secretion of GCs from the adrenal cortex, as a consequence of HPA activation. Additionally, neural regulation of PNMT is mediated by splanchnic nerve innervation as part of the SA system (Kvetňanský \& Pacák 1995). It is suggested that the SA system can also be programmed for development of hypertension, with subsequent effects within the adrenal medulla, such as enhanced activity of chromaffin cells as early as 1 week of age (Molendi-Coste et al. 2006). Thus, increased activity of adrenal chromaffin cells may be dependent on dysregulation of either one or both the HPA and SA axes. In the SHR, a genetic model of hypertension, there is enhanced HPA activity mediated by increased levels of CRF mRNA, plasma ACTH and corticosterone (Djordjevic et al. 2007), as well as increased SA activity after periods of stress through increased levels of plasma epinephrine and norepinephrine (Kvetňanský \& Pacák 1995). There is also increased activity of transcription factors Egr-1 and GR coincident with enhanced adrenal PNMT gene expression in SHR (Nguyen et al. 2009). The elevated activity of Egr-1 and GR observed in this study supports the notion of enhanced activity of both the HPA and SA axes in GCprogrammed offspring, leading to increased PNMT expression and elevated epinephrine levels, which contribute to development of adult hypertension. As a key component of the neuroendocrine response to stress, epinephrine synthesis and secretion are both regulated by the HPA and SA axes (Axelrod 1976, Wong 2006). The HPA axis is required for adrenergic activation of PNMT gene expression (Kvetňanský \& Pacák 1995), mediated via functional GC response elements (GREs) on the PNMT promoter which require activation by GR and also facilitate the recruitment of other transcription factors such as Egr-1 and AP-2 (Tai et al. 2002). PNMT expression in the adrenal medulla is also regulated by the SA system via splanchnic nerve innervation; this involves the neurotransmitters acetylcholine and pituitary adenylate cyclase-activating polypeptide (PACAP), whose signaling cascades regulate the transcription factors Egr-1, Sp1 and AP-2 (Morita et al. 1996, Wong \& Tai 2002, Tai \& Wong 2003, Tai et al. 2010b). Egr-1, expressed exclusively in adrenergic cells of the adrenal medulla (Criado et al. 1997), is well-known for its regulatory role in the expression of genes involved in catecholamine biosynthesis, particularly its induction associated with elevated PNMT expression in pheochromocytoma (Isobe et al. 2000). Also, it has been shown to be induced in response to stress in vivo together with GR (Tai et al. 2007). Furthermore, Egr-1, GR and AP-2 have been shown to synergistically activate the PNMT promoter (Wong et al. 1998, Tai et al. 2002, 2007), reinforcing the notion that elevated expression of these transcriptional regulators alter PNMT promoter activity, resulting in increased PNMT expression and epinephrine synthesis in GCprogrammed offspring.

This study shows evidence of a molecular mechanism involved in the dysregulation of adrenal PNMT expression within a fetal programming model of hypertension, mediated by prenatal GC administration. Increased expression of the transcription factors Egr-1 and GR in the adrenal gland are associated with elevated PNMT expression levels, which subsequently lead to elevated epinephrine biosynthesis, likely contributing to the hypertensive phenotype of DEX-treated offspring. These results suggest that altered transcriptional regulation of PNMT expression through Egr-1 and GR is an important

Published by Bioscientifica Ltd 
component of GC-induced fetal programming of adult hypertension, and this is mediated by enhanced activity of the sympathoadrenal system.

\section{Declaration of interest}

The authors declare that there is no conflict of interest that could be perceived as prejudicing the impartiality of the research reported.

\section{Funding}

This work was supported by funding from the Canadian Institutes for Health Research (Grant IHD98766) and the NOSM Research Development Fund.

\section{Acknowledgements}

The authors wish to thank Collin J Byrne for his assistance with statistical data analyses for the blood pressure and weight measurements.

\section{References}

Alexander BT 2007 Divergent origins of slow fetal growth: relevance to adult cardiovascular disease. Hypertension 50 465-466. (doi:10.1161/ HYPERTENSIONAHA.107.094029)

Alexander BT, Dasinger JH \& Intapad S 2015 Fetal programming and cardiovascular pathology. Comprehensive Physiology 5 997-1025. (doi:10.1002/cphy.c140036)

Axelrod J 1976 Catecholamines and hypertension. Clinical Science and Molecular Medicine 51 415s-421s.

Barker DJ 1995 The fetal and infant origins of disease. European Journal of Clinical Investigation 25 457-463. (doi:10.1111/j.1365-2362.1995. tb01730.x)

Barker DJP, Bagby SP \& Hanson MA 2006 Mechanisms of disease: in utero programming in the pathogenesis of hypertension. Nature Clinical Practice. Nephrology 2 700-707. (doi:10.1038/ncpneph0344)

Baum M 2010 Overview of chronic kidney disease in children. Current Opinion in Pediatrics 22 158-160. (doi:10.1097/MOP. 0b013e32833695cb)

Benediktsson R, Lindsay RS, Noble J, Seckl JR \& Edwards CR 1993 Glucocorticoid exposure in utero: new model for adult hypertension. Lancet 341 339-341. (doi:10.1016/0140-6736(93)90138-7)

Borkowski K \& Quinn P 1984 Adrenaline and the development of genetic hypertension. Journal of Hypertension 2 (Suppl 2) S81-S83.

Bouret SG 2009 Early life origins of obesity: role of hypothalamic programming. Journal of Pediatric Gastroenterology and Nutrition 48(Suppl 1) S31-S38. (doi:10.1097/MPG.0b013e3181977375)

Boyne MS, Woollard A, Phillips DIW, Taylor-Bryan C, Bennett FI, Osmond C, Thomas TYR, Wilks RJ \& Forrester TE 2009 The association of hypothalamic-pituitary-adrenal axis activity and blood pressure in an Afro-Caribbean population. Psychoneuroendocrinology 34 736-742. (doi:10.1016/j.psyneuen.2008.12.005)

Buühler F, Amann FW, Bolli P, Hulthén L, Kiowski W, Landmann R \& Bürgisser E 1982 Elevated adrenaline and increased $\alpha$-adrenoceptormediated vasoconstriction in essential hypertension. Journal of Cardiovascular Pharmacology 4 S134-S138.

Cottrell EC \& Seckl JR 2009 Prenatal stress, glucocorticoids and the programming of adult disease. Frontiers in Behavioral Neuroscience 319. (doi:10.3389/neuro.08.019.2009)
Criado M, Domínguez del Toro E, Carrasco-Serrano C, Smillie FI, Juíz JM, Viniegra S \& Ballesta JJ 1997 Differential expression of $\alpha$-bungarotoxinsensitive neuronal nicotinic receptors in adrenergic chromaffin cells: a role for transcription factor Egr-1. Journal of Neuroscience $\mathbf{1 7}$ 6554-6564.

Djordjevic J, Vuckovic T, Jasnic N \& Cvijic G 2007 Effect of various stressors on the blood ACTH and corticosterone concentration in normotensive Wistar and spontaneously hypertensive Wistar-Kyoto rats. General and Comparative Endocrinology 153 217-220. (doi:10.1016/j.ygcen.2007. 02.004)

Dodic M, Hantzis V, Duncan J, Rees S, Koukoulas I, Johnson K, Wintour EM \& Moritz K 2002 Programming effects of short prenatal exposure to cortisol. FASEB Journal 16 1017-1026. (doi:10.1096/fj.01-1045com)

Drake AJ, Tang JI \& Nyirenda MJ 2007 Mechanisms underlying the role of glucocorticoids in the early life programming of adult disease. Clinical Science 113 219-232. (doi:10.1042/CS20070107)

Ebert SN, Balt S \& Hunter J 1994 Egr-1 activation of rat adrenal phenylethanolamine $N$-methyltransferase gene. Journal of Biological Chemistry $26920885-20898$.

Edwards CR, Benediktsson R, Lindsay RS \& Seckl JR 1993 Dysfunction of placental glucocorticoid barrier: link between fetal environment and adult hypertension? Lancet 341 355-357. (doi:10.1016/0140-6736 (93)90148-A)

Feng M, Whitesall S, Zhang Y, Beibel M, D’Alecy L \& DiPetrillo K 2008 Validation of volume-pressure recording tail-cuff blood pressure measurements. American Journal of Hypertension 21 1288-1291. (doi:10.1038/ajh.2008.301)

Goyal R, Goyal D, Leitzke A, Gheorghe CP \& Longo LD 2010 Brain renin-angiotensin system: fetal epigenetic programming by maternal protein restriction during pregnancy. Reproductive Sciences 17 227-238. (doi:10.1177/1933719109351935)

Haan C \& Behrmann I 2007 A cost effective non-commercial ECL-solution for Western blot detections yielding strong signals and low background. Journal of Immunological Methods 318 11-19. (doi:10.1016/ j.jim.2006.07.027)

Habib S \& Gattineni J 2011 Evidence that prenatal programming of hypertension by dietary protein deprivation Is mediated by fetal glucocorticoid exposure. Journal of Hypertension 24 96-101. (doi:10.1038/ajh.2010.177)

Her S, Claycomb R, Tai TC \& Wong DL 2003 Regulation of the rat phenylethanolamine $N$-methyltransferase gene by transcription factors Sp1 and MAZ. Molecular Pharmacology 64 1180-1188. (doi:10.1124/mol. 64.5.1180)

Hoehe MR, Plaetke R, Otterud B, Stauffer D, Holik J, Byerley WF, Baetge EE, Gershon ES \& Lalouel J 1992 Genetic linkage of the human gene for phenylethanolamine $N$-methyltransferase (PNMT), the adrenaline synthesizing enzyme, to DNA markers on chromosome 17q21-q22. Human Molecular Genetics 1 175-178. (doi:10.1093/hmg/1. 3.175)

Isobe K, Nakai T, Yashiro T, Nanmoku T, Yukimasa N, Ikezawa T, Suzuki E, Takekoshi K \& Nomura F 2000 Enhanced expression of mRNA coding for the adrenaline-synthesizing enzyme phenylethanolamine- $N$-methyl transferase in adrenaline-secreting pheochromocytomas. Journal of Urology 163 357-362. (doi:10.1016/ S0022-5347(05)68051-2)

Jablonskis LT \& Howe PR 1994 Elevated plasma adrenaline in spontaneously hypertensive rats. Blood Pressure 3 106-111. (doi:10.3109/ 08037059409101529)

Johansson S, Norman M, Legnevall L, Dalmaz Y, Lagercrantz H \& Vanpée M 2007 Increased catecholamines and heart rate in children with low birth weight: perinatal contributions to sympathoadrenal overactivity. Journal of Internal Medicine 261 480-487. (doi:10.1111/j.1365-2796. 2007.01776.x)

Kaneda N, Ichinose H, Kobayashi K, Oka K, Kishi F, Nakazawa A Kurosawa Y, Fujita K \& Nagatsu T 1988 Molecular cloning of cDNA and chromosomal assignment of the gene for human phenylethanolamine 
$\mathrm{N}$-methyltransferase, the enzyme for epinephrine biosynthesis. Journal of Biological Chemistry 263 7672-7677.

Karemaker R, Heijnen CJ, Veen S, Baerts W, Samsom J, Visser GH, Kavelaars A, van Doornen LJP \& van Bel F 2006 Differences in behavioral outcome and motor development at school age after neonatal treatment for chronic lung disease with dexamethasone versus hydrocortisone. Pediatric Research 60 745-750. (doi:10.1203/01. pdr.0000246200.76860.de)

Khurana S, Byrne Collin J., Mercier S, Lamothe J, Williamson CR, Grandbois J \& Tai TC 2015 The role of adrenal hormones in the fetal programming of hypertension. In Adrenal Glands and Cortex: Structural Characteristics, Hormones and Related Disorders. Chapter 10, Ed G Santulli. Hauppauge, New York, NY, USA: Nova publishers.

Koike G, Jacob HJ, Krieger JE, Szpirer C, Hoehe MR, Horiuchi M \& Dzau VJ 1995 Investigation of the phenylethanolamine $N$-methyltransferase gene as a candidate gene for hypertension. Hypertension 26 595-601. (doi:10.1161/01.HYP.26.4.595)

Kvetňanský R, Pacák K, Fukuhara K, Viskupič E, Hiremagalur B, Nankova B, Goldstein DS, Sabban EL \& Kopin IJ 1995 Sympathoadrenal system in stress. Annals of New York Academy of Sciences 771 131-158. (doi:10.1111/j.1749-6632.1995.tb44676.x)

Lesage J, Del-Favero F, Leonhardt M, Louvart H, Maccari S, Vieau D \& Darnaudery M 2004 Prenatal stress induces intrauterine growth restriction and programmes glucose intolerance and feeding behaviour disturbances in the aged rat. Journal of Endocrinology 181 291-296. (doi:10.1677/joe.0.1810291)

Lesage J, Sebaai N, Leonhardt M, Dutriez-Casteloot I, Breton C, Deloof S \& Vieau D 2006 Perinatal maternal undernutrition programs the offspring hypothalamo-pituitary-adrenal (HPA) axis. Stress 9 183-198. (doi:10.1080/10253890601056192)

Levitt NS, Lindsay RS, Holmes MC \& Seckl JR 1996 Dexamethasone in the last week of pregnancy attenuates hippocampal glucocorticoid receptor gene expression and elevates blood pressure in the adult offspring in the rat. Neuroendocrinology 64 412-418. (doi:10.1159/ 000127146)

Ligi I, Grandvuillemin I, Andres V, Dignat-George F \& Simeoni U 2010 Low birth weight infants and the developmental programming of hypertension: a focus on vascular factors. Seminars in Perinatology 34 188-192. (doi:10.1053/j.semperi.2010.02.002)

Molendi-Coste O, Grumolato L, Laborie C, Lesage J, Maubert E, Ghzili H, Vaudry H, Anouar Y, Breton C \& Vieau D 2006 Maternal perinatal undernutrition alters neuronal and neuroendocrine differentiation in the rat adrenal medulla at weaning. Endocrinology 147 3050-3059. (doi:10.1210/en.2005-1331)

Morita K, Bell R, Siddall B \& Wong D 1996 Neural stimulation of Egr-1 messenger RNA expression in rat adrenal gland: possible relation to phenylethanolamine $\mathrm{N}$-methyltransferase gene regulation. Journal of Phamacology and Experimental Therapeutics 279 379-385.

Nguyen P, Peltsch H, de Wit J, Crispo J, Ubriaco G, Eibl J \& Tai TC 2009 Regulation of the phenylethanolamine $\mathrm{N}$-methyltransferase gene in the adrenal gland of the spontaneous hypertensive rat. Neuroscience Letters 461 280-284. (doi:10.1016/j.neulet.2009.06.022)

Nyirenda MJ, Welberg LA \& Seckl JR 2001 Programming hyperglycaemia in the rat through prenatal exposure to glucocorticoids-fetal effect or maternal influence? Journal of Endocrinology 170 653-660. (doi:10.1677/joe.0.1700653)

Oliveira M, Bessa JM, Mesquita A, Tavares H, Carvalho A, Silva R, Pêgo JM, Cerqueira JJ, Palha JA, Almeida OFX et al. 2006 Induction of a hyperanxious state by antenatal dexamethasone: a case for less detrimental natural corticosteroids. Biological Psychiatry 59 844-852. (doi:10.1016/j.biopsych.2005.08.020)

O'Regan D \& Kenyon C 2004 Glucocorticoid exposure in late gestation in the rat permanently programs gender-specific differences in adult cardiovascular and metabolic physiology. American Journal of Physiology Endocrinology and Metabolism 287 863-870. (doi:10.1152/ajpendo. 00137.2004)
O'Regan D, Kenyon CJ, Seckl JR \& Holmes MC 2008 Prenatal dexamethasone 'programmes' hypotension, but stress-induced hypertension in adult offspring. Journal of Endocrinology 196 343-352. (doi:10.1677/ JOE-07-0327)

Ortiz LA, Quan A, Zarzar F, Weinberg A \& Baum M 2002 Prenatal dexamethasone programs hypertension and renal injury in the rat. Hypertension 41 328-334. (doi:10.1161/01.HYP.0000049763. 51269.51)

Pladys P \& Sennlaub F 2005 Microvascular rarefaction and decreased angiogenesis in rats with fetal programming of hypertension associated with exposure to a low-protein diet in utero. American Journal of Physiology Regulatory, Integrative and Comparative Physiology 5 1580-1588. (doi:10.1152/ajpregu.00031.2005)

Reja V, Goodchild K \& Pilowsky PM 2002 Catecholamine-related gene expression correlates with blood pressures in SHR. Hypertension $\mathbf{4 0}$ 342-347. (doi:10.1161/01.HYP.0000027684.06638.63)

Shaltout HA, Figueroa JP, Rose JC, Diz DI \& Chappell MC 2009 Alterations in circulatory and renal angiotensin-converting enzyme and angiotensin-converting enzyme 2 in fetal programmed hypertension. Hypertension 53 404-408. (doi:10.1161/HYPERTENSIONAHA.108. 124339)

Singh RR, Cullen-McEwen LA, Kett MM, Boon WM, Dowling J, Bertram JF \& Moritz KM 2007 Prenatal corticosterone exposure results in altered AT1/AT2, nephron deficit and hypertension in the rat offspring. Journal of Physiology $\mathbf{5 7 9}$ 503-513. (doi:10.1113/jphysiol. 2006.125773)

Tai TC \& Wong DL 2003 Protein kinase A and protein kinase C signaling pathway interaction in phenylethanolamine $\mathrm{N}$-methyltransferase gene regulation. Journal of Neurochemistry 85 816-829. (doi:10.1046/j.14714159.2003.01728.x)

Tai TC, Claycomb R, Her S, Bloom AK \& Wong DL 2002 Glucocorticoid responsiveness of the rat phenylethanolamine $\mathrm{N}$-methyltransferase gene. Molecular Pharmacology 61 1385-1392. (doi:10.1124/mol.61.6. 1385)

Tai TC, Claycomb R, Siddall BJ, Bell RA, Kvetnansky R \& Wong DL 2007 Stress-induced changes in epinephrine expression in the adrenal medulla in vivo. Journal of Neurochemistry 101 1108-1118. (doi:10.1111/ j.1471-4159.2007.04484.x)

Tai TC, Wong-Faull DC, Claycomb R \& Wong DL 2009 Hypoxic stress-induced changes in adrenergic function: role of HIF1 $\alpha$. Journal of Neurochemistry 109 513-524. (doi:10.1111/j.1471-4159.2009. 05978.x)

Tai TC, Wong-Faull DC, Claycomb R \& Wong DL 2010a Hypoxia and adrenergic function: molecular mechanisms related to Egr-1 and Sp1 activation. Brain Research 1353 14-27. (doi:10.1016/j.brainres.2010.07. 036)

Tai TC, Wong-Faull DC, Claycomb R, Aborn JL \& Wong DL $2010 b$ PACAP-regulated phenylethanolamine $N$-methyltransferase gene expression. Journal of Neurochemistry 115 1195-1205. (doi:10.1111/ j.1471-4159.2010.07005.x)

Vehaskari VM \& Woods LL 2005 Prenatal programming of hypertension: lessons from experimental models. Journal of the American Society of Nephrology 16 2545-2556. (doi:10.1681/ASN.2005030300)

Wong DL 2006 Epinephrine biosynthesis: hormonal and neural control during stress. Cellular and Molecular Neurobiology 26 891-900. (doi:10.1007/s10571-006-9056-6)

Wong D \& Tai TC 2002 Neural mechanisms regulating phenylethanolamine $N$-methyltransferase gene expression. In Catecholamine Research: From Moleculer Insights to Clinical Medicine, pp 135-138. Eds T Nagatsu, T Nabeshima, R McCarty \& DS Goldstein. Berlin, Germany: Springer.

Wong DL, Siddall BJ, Ebert SN, Bell RA \& Her S 1998 Phenylethanolamine $\mathrm{N}$-methyltransferase gene expression: synergistic activation by Egr-1, AP-2 and the glucocorticoid receptor. Brain Research. Molecular Brain Research 61 154-161. (doi:10.1016/S0169-328X(98)00225-3)

Wong DL, Tai TC, Wong-Faull DC, Claycomb R \& Kvetnanský R 2008 Adrenergic responses to stress: transcriptional and post-transcriptional

Published by Bioscientifica Ltd. 
changes. Annals of the New York Academy of Science 1148 249-256. (doi:10.1196/annals.1410.048)

Woods L \& Weeks D 2005 Prenatal programming of adult blood pressure: role of maternal corticosteroids. American Journal of Physiology. Regulatory, Integrative and Comparative Physiology 289 955-962. (doi:10.1152/ajpregu.00455.2004)
Wyrwoll CS, Mark PJ \& Waddell BJ 2007 Developmental programming of renal glucocorticoid sensitivity and the renin-angiotensin system. Hypertension 50 579-584. (doi:10.1161/HYPERTENSIONAHA.107. 091603)

Young JB 2002 Programming of sympathoadrenal function. Trends in Endocrinology and Metabolism 13381-385. (doi:10.1016/S1043-2760(02)00661-6)

Received in final form 11 September 2014

Accepted 14 September 2015
Published by Bioscientifica Ltd. 